\title{
An Analysis of the Influence of Informal Grouping Dynamics on Organizational Performance in the Nigerian Telecommunication Sector
}

\author{
Christopher Akpotu ${ }^{1} \&$ Ginah O. Ginah ${ }^{2}$ \\ ${ }^{1}$ Department of Business Administration, Niger-Delta University, Wilberforce Island, Amassoma, Nigeria. \\ ${ }^{2}$ Chen Consult, Management and Marketing Research PortHarcourt, Nigeria \\ Correspondence: Christopher Akpotu, Dept of Bus Admin Niger Delta University, Wilberforce Island, Amassoma.
}

\author{
Received: March 27, 2015 \\ Accepted: April 10, 2015 \\ Available online: June 5, 2015 \\ doi:10.11114/ijsss.v3i4.861 \\ URL: http://dx.doi.org/10.11114/ijsss.v3i4.861
}

\begin{abstract}
There is exponential growth in number of studies focused on performance of firms considering the increased level of competitiveness. Much of the studies so far had shown concern for factors within the environment of organization and how they link performance. This notwithstanding, this study is focused on behavioural dynamics of informal grouping and its link with performance in the telecommunication subsector of the Nigerian economy. The survey instrument was used in generating data from a sample of 112 sample subjects. From the inferential analysis, a strong positive and significant relationship exists between informal group dynamics and performance. Value reinforcement behavior dimension has more weight with $\rho=0.412$ amongst other dimensions of informal group dynamics. It was concluded that informal groups are social network within work organizations that ultimately serve as a strategic means of enhancing performance through innovativeness and responsiveness. It was therefore recommended that informal groups should subsist at work in as much as their existence is regulated by organizational policies.
\end{abstract}

Keywords: Informal Group, Knowledge Enrichment, Mentoring, Value Reinforcement, Social Interaction.

\section{Introduction}

There is fast growing literature with empirical evidence on informal groups at work (Johnnie, 1996; Jaja and Chukwuigwe, 1998; Baraso, 1999; Nakisbe, 2004; Parasunaman 2007). The various thoughts though have shown conceptual variegation, they have commonly agreed that informal groups pervade the various levels and functions of work with a view to emphasizing the interest of group members. According to Rosenfield, et al, (2002) informal group presence in work organizations is fast becoming prominent that there should be a strategic organizational effort aimed at formalizing their presence. The reason behind his position is that, in this season of increased competitiveness, informal groups will serve as a veritable instrument for evolving the entrepreneurial culture that helps to promote innovative practices. Van Vianen and DeDrew (2001) have posited that employees for the purpose of individualistic practices will not ordinarily be psychologically disposed to sharing their skills and competencies. But if collectivism is to be experienced as a more functional approach to communal sharing both in terms of resources and knowledge asset, they strongly believed that encouraging informal groups facilitates knowledge sharing which is a precursor for innovativeness, continuous process improvement and quality practices. While this thinking subsists, Van Vianen and DeDrew (2001) are of the view that informal groupings when viewed on the degree of their being informal, creates a managerial burden informally for managers who require additional competences to manage their activities. Informal groups exist to achieve group interest which may not necessarily be in tandem with the overall goals of the organisation. This goal diversity often times creates conflict of interest which managers must resolve. The inability of organizational managers to cope with the ever present interest of informal groups will create a dysfunctional work climate. Barayam and Mephil (2007) espoused establishing viable relationships among work members that are recognized representatives of social work teams that are organizational goal directed. However, they expressed a conceptual skepticism in examining the similarity between work teams and informal group. Their skepticisms were on the premise that informal groups whose interest or expectations are impeded by organizational policies and strategies will encourage, through their collective actions, dysfunctional outcomes. This equally asserts their degree of informality which was earlier mentioned.

Conversely, Farveh and Osseh (2012) believed strongly about informal groups' inability to knowingly create a 
negatively oriented employee-management relationship. Infact, Rogers, (2007) noted that apart from striving to achieve group interest and most likely interest of their individual members they constitute a basis for creative work actions that maximize organizational effort at optimal performance. Exploring and unlocking the potentials conveyed by informal groups at work is fast resulting to a conceptual reconfiguration, perhaps with a more strategic thinking on how both the groups themselves and management could possibly co-exist and managers relying on them for competitive advantage. While these multi perspective remains, the need to establish an empirical link between informal groups and performance is imperative, therefore, this study is aimed at showing the relationship between informal group dynamics and performance.

\subsection{Justification of the Study}

Expanding the knowledge frontiers and understanding of work place actions and inaction that are incentives to system functionality has been heightened than ever before. The reasons are not far fetched; competitiveness has attained a phenomenal level that if not strategically and holistically driven by managers might create an entropic state for organization. Similarly the inmate behavioural expression are seemingly assuming prominence in employee day by day involvement in organizational activities and their consideration as strategic resource requires that all such behavioural niceties should be given indepth analysis with a view to creating understanding and eventual decision making. It is also important that the evolving nature of the sector should be viewed rigorously especially the socio-technical forms that are likely to propel functional outcomes especially in the light of the huge resources that are committed by operators in the sector.

\subsection{Objectives of the Study}

The general purpose of the study is to examine the influence of informal groupings as a component of organizational politics on organizational performance. Specifically, the objectives aimed are as follows:

a. $\quad$ To find the extent to which social interaction behaviour relates with organizational performance.

b. To determine the extent to which knowledge enrichment behaviour relates with organizational performance.

c. To know the extent to which value reinforcement behavior relates with organizational performance.

d. To ascertain the extent to which member mentoring behaviour relates with organizational performance.

\section{Literature Review}

\subsection{Informal Group Dynamics}

Baridam (2008) has viewed groups within work context as having distinguishable characteristic of common interaction and shared values that promote their identity. They share common perception, ideologies, values, beliefs and norms which contribute to their predictability. Simply, this means that an employee who belongs to a group is influenced by such values which are capable of reinforcing his commitment. Valder (2010) noted that informal group values are seemingly mechanistic and members of such group are glued in adherence to their prescriptions. It is in this vein that member rate of compliance is equally noticeable not just at the level of the individual but in their behavior towards work tasks that may be assigned by managers.

Gilla's (2007) model of group behavior noted that groups can set their own norms, values and beliefs different from that of the entire organization and members act on them with a view to enhancing their chances at individual goals and likely using them to attain organization wide goals. Jaja \& Amingo (2009) in their discourse on groups at work argues that the evolution of informal groupings within work organizations evoke managerial fears which are essentially germane when viewed against the backdrop of the selfish desire of individual members but has also gone ahead to state that managers ability to ensure that these desires are harnessed and ensuring a cohesive climate that promotes work ideals is imperative. The long-term implication of cohesiveness among informal group members is behavioural dynamism that reminisce common tendencies which in most cases provides the impetus for goals either for members or their work organization. Jeremi (2011) noted that though informal groups have shown conservatism in striving for group goals; they are barred by social exchange practices, which are characteristically built on the tenets of reciprocity. In other words, if informal groups are allowed to function within organizations which ordinarily should be formalized, their capacity to translate their presence to meaningful outcomes through their shared beliefs must be underscored. Informal groups at work according to Churchill et al (2007) are strategic to the goal drive as they are a vital resource. Barney (2002) stressed that organizations need to exploit and harness resources to achieve competitive edge. This has made it increasingly important for recognition of informal groups which Churchill espoused. They have a predisposition towards achieving the goals of the organization as they commonly share ideas and enrich their capabilities.

\subsection{Organizational Performance}

The organization performance literature is robust with multi-perspectives. These perspectives are however expected 
when viewed in the light of the multi-disciplinary and functional make-up of organizations. They have essentially described performance in line with their functional expectations. All the same, these have not shifted from a common conceptual thinking that, performance relates to expected and desired outcomes resulting from aggregate activities, roles, responsibilities and functions carried out by organization through her workforce. Importantly, while the conceptual rage lasts, Kaplan \& Norton (1992) have provided a more embracing framework that have assisted and channeled the debate on performance measures. Their framework provides a functional guide that permits the definition of measures based on functional areas. In line with extant position, this study performance measures are process oriented measures which are non-financial. From the extensive review of the theoretical context, the study has used innovativeness and responsiveness as measures of performance.

\subsection{Link between Informal Group Dynamics and Organisational Performance}

In order to achieve performance a company may need to exploit their most valuable resource which is a source for giving the company a competitive edge (Barney, 2002). Miller (1983), assumes that the degree of entrepreneurship of a company can be seen as the extent the individuals in the company, departments or the firm as a whole take risks and innovate through practical knowledge sharing. They expectedly create a continuous learning platform that culminates to robust and enhanced knowledge experiences. Informal group helps in gaining competitive edge through their knowledge enhancement programmes targeted at members. Levin \& Cross (2004) had argued extensively that work place social networks especially informally created ones have an informal resolve to enrich the capacity of members and strengthen their capabilities that brings them close to achieving career goals.

While there is an extensive body of literature about the advantages of developing effective workplace groupings and employee performance (Sparrowe, et al., 2001; Totterdell, Holman, \& Hukin, 2008), little is known about their implications on driving competitiveness and overall organisational performance. Aguero (2007) contend that the discourse on informal groups at work so far has undermined its ability to encourage group members toward achieving member and group goals through mentoring behavior. They learn easily through an affective attitude shared amongst members who willingly ensure capacity building. However while Aguero's position is limited to attainment of individual member and group goals, the author did not draw a link on how it can influence the macro organisational expectations. Further, it has created a gap in terms of understanding organizational factors that enhance behavioural dynamics that may strategically act on set goals therefore we hypothesize as follows:

$\boldsymbol{H}_{01}$ : There is no significant relationship between social interaction behaviour of informal groups and organisational performance

$\boldsymbol{H}_{02}$ : $\quad$ There is no significant relationship between knowledge enrichment behaviour and organisational performance

$\boldsymbol{H}_{03}$ : $\quad$ There is no significant relationship between value reinforcement behaviour and organisational performance

$\boldsymbol{H}_{04}$ : There is no significant relationship between member mentoring behaviour and organisational performance

\section{Methodology}

The debate on research approaches is interestingly expansive; essentially, methodology is at the centre of the debate so far as it provides the basis for evolving knowledge as targeted by researchers (Daniel, 1996, Borrego, 2000, Creswell, 2002). All the same, the approach should be objective, causal, cumulative and progressive, emphasizing reliability and external validity (Mitroff and Kilmann, 1978, Lincoln, 1985, Tashakori, 2003; Dabbagh and Mensce, 2006). In this instance the methodology adopted is the positivist that permits the application of quantitative methods. In this way hypothesized statements are made apriori and analysed for inference.

\subsection{Measurement}

The constructs examined in this study were conceptualized by researcher and also adapted from extant literature with some modification to suit the context. From existing literature, the informal group dynamics was measured using Gabbells (2006) 14 item scale which was validated in Jaja (2007). For firm performance, Lenny (2007) 16 items scale was adapted for use and had shown reliability with an alpha of 0.81 when used by Danba and Elliot (2009). All items were measured using the five point Likert scale of Strongly Agree $=5$ to Strongly Disagree $=1$.

\section{Results}

Correlation Matrix on the Relationship between Informational Group Dynamics and Organisational Performance

\begin{tabular}{|c|c|c|c|c|c|c|c|}
\hline \multicolumn{3}{|c|}{1} & 2 & 3 & 4 & 5 & 6 \\
\hline Social Inter & nal Behaviour & 1.00 & -13 & $.55^{*}$ & $.41 *$ & $.55^{* *}$ & $.47^{*}$ \\
\hline $\begin{array}{l}\text { Knowledge } \\
\text { Behaviour }\end{array}$ & Enrichment & & 1.00 & $.20 *$ & $.24 * *$ & $.20 * *$ & $.33^{*}$ \\
\hline Value & Reinforcement & & & 1.00 & $.82 * *$ & $.82 *$ & $.47 * *$ \\
\hline
\end{tabular}




\begin{tabular}{|c|c|c|c|}
\hline \multicolumn{4}{|l|}{ Behaviour } \\
\hline Member Mentoring Behaviour & 1.00 & $.78^{*}$ & $.88^{* *}$ \\
\hline Innovativeness & & 1.00 & $.39 *$ \\
\hline Responsiveness & & & 1.00 \\
\hline
\end{tabular}

The results in table 1 are correlated result on the relationship of the different dimensions of informal group dynamics and organizational performance measures. All the dimensions of informal group dynamics which includes social interaction behaviour, knowledge enrichment behaviour, value reinforcement behaviour and member mentoring behaviour have significant positive relationship at $\rho=0.01$ and 0.05 with organizational performance measures of innovativeness and responsiveness in the studied sector. The implication of the results is that the null hypotheses stated are rejected and the alternates are accepted.

Table 2(a). Coefficient from Regression Analysis of the Studied Variables Model Summary

\begin{tabular}{ccccccc}
\hline Model & $\mathrm{R}$ & $\mathrm{R}^{2}$ & $\mathrm{AdjR}^{2}$ & Std Error Est & F. Charge & Sig \\
\hline 1 & .516 & .266 & -0.224 & 2.0876 & 46.234 & .000 \\
\hline
\end{tabular}

a. Predictors (constant) Social Interactional Behaviour, Knowledge Enrichment Behaviour, Value Reinforcement Behaviour, Member Mentoring Behaviour

\begin{tabular}{|c|c|c|c|c|c|c|c|}
\hline & & & $\begin{array}{r}\text { Unst } \\
\mathrm{co}\end{array}$ & $\begin{array}{l}\text { dardized } \\
\text { icient }\end{array}$ & $\begin{array}{l}\text { Standardized } \\
\text { coefficient }\end{array}$ & & \\
\hline \multirow{8}{*}{1} & \multicolumn{2}{|c|}{ Model } & Beta & Std Error & Beta & $\mathrm{t}$ & Sig \\
\hline & Constant & & -5.238 & 1.792 & & -2.656 & .010 \\
\hline & 1. Social & Interactional & 477 & 0.425 & .154 & 1.123 & .002 \\
\hline & Behaviour & & 1.551 & 0.752 & .345 & 2.016 & .000 \\
\hline & 2. Knowledge & Enrichment & 0.117 & 0.566 & 036 & 0.207 & .000 \\
\hline & Behaviour & & 1.643 & 0.604 & .569 & 2.720 & .032 \\
\hline & $\begin{array}{l}\text { 3. Value } \\
\text { Behaviour }\end{array}$ & Reinforcement & & & & & \\
\hline & $\begin{array}{l}\text { 4. Member } \\
\text { Behaviour }\end{array}$ & Mentoring & & & & & \\
\hline
\end{tabular}

Dependent Variable: Organisational Performance

Table 2 shows the regression results of the study and have pointed out that when informal group dynamics are regressed against organizational performance, a strong and positive relationship is the case in the telecommunication sector. From the results, an $\mathrm{R}$ value of .516 show that a moderate relationship exist between the examined variables and up to $26.6 \%$ of the variability in the criterion is explained by the predictor variable. The remaining $73.4 \%$ is not explained, because the remaining part of the variability in organizational performance is related to other variables which are not part of this model.

Further, the magnitude of the influence of the dimensions of informal dynamics which includes, social interactional behaviour, knowledge enrichment behaviour, value reinforcement behaviour and member mentoring on the criterion variable which is organizational performance is also shown. The results shows that member mentoring behavior has the highest weight among the components of informal group dynamics with a $\beta$ value of $0.569 ; \mathrm{t}=2.720$. This was followed with the knowledge enrichment behaviour with $\beta=0.345 ; \mathrm{t}=2.016$.

\section{Discussion}

The study has investigated the extent to which informal group dynamics at work links organizational performance. From the study results, it is indicative of a renewed conceptual focus on the influence of informal group on organizational desired outcome which are hitherto seen as impeding performance in organizations (Morrison, 2005; Jackson \& Miller, 2009). First, social interaction has a positive and significant relationship with innovativeness and responsiveness in the study. This is in support of Peters and Lucy (2008) position on social ties among workers as a source of psychological and mental empowerment for performance. Second, knowledge enrichment behaviour has a weak but positive and significant link with measures of organizational performance. Extant literature has a broad recognition of how knowledge asset of organization is key to their competitive ability (Gray et al 2000; Kavcic \& Ivankorich, 2006; Chaharbagi and Cripps, 2006; Pedrini, 2007). Expectedly, the study findings agree with existing 
position. Knowledge enrichment behaviour is practiced amongst group members as a means of buffering their innovative tendencies and organizational ability to respond promptly to the demands of the market place. Third, values and shared beliefs have been described by Baridam (2006) as thematic amongst informal groups. Moro (2009) also argued that within informal groups, they perpetuate strong values and norms that strengthen and sustain their fraternity towards achieving group goals. It was found in the study that a very strong positive and significant relationship exists between value reinforcement behaviour among group members and innovativeness and responsiveness measures of performance. Informal group members expectedly ensure that group pedigree is sustained through positive values reinforcement that emphasizes their interest as well meaning. It encourages individual employees to show commitment to work goals. Finally, the results on member mentoring are assertive of the willingness of group members to mentor themselves. This finding is a shift form the work of (Barego, 2000; Faweh and Osseh, 2012) who argued through their empirical study that since informal group members are superficially loyal to the group authority, they barely show concern for others that do not bear their identity and this impedes their capacity to collectively achieve goals. The study results show a strong, positive and significant link between member mentoring and organizational performance. Group members are offered guidance and support and creating the desired work climate that is an incentive for subordinate members of informal group, which they found interesting to build capacity and remain responsive to work tasks. The result of the standardized beta coefficient are also assertive in relation to weight of member mentoring behaviour and conform to Bazal and Ledon (2011) position on mentors at work as facilitators of training and development programmes which broadens the learning capabilities of beneficiary who are characteristically committed to their chosen mentors.

\section{Conclusion/Policy Implications}

There exist several plausible discussions on informal grouping with many expressing dysfunctional implications. This aspect of the discourse have pervaded the thinking on informal groups which are largely seen as perpetuating group interest at the expense of the organization that provides the playing ground. In this vein this study primarily investigated the link between informal group's dynamics and performance of firms in the telecommunication sector. From the data obtained and analysed what is clear is that, the informal group dynamic components social interaction behavior, knowledge enrichment behaviour, value reinforcement behaviour and member mentoring behaviour are critical to the overall performance of sector. Their strategic implication is underscored in their ability to strongly relate with performance in terms of innovativeness and responsiveness. They commonly fraternize to enrich their work content and share knowledge that ultimately enhances performance goals. What this holds for the organization is that managers/operators should allow a flexible work climate that encourage common basis for group as it will help build on the confidence they need to unleash their creative potential. Importantly, as firm strive to enrich their knowledge reservoir for competitive position; informal groups are proven facilitators of knowledge acquisition and sharing amongst group-members which is a likely necessity for knowledge enrichment. If literature position on mentoring as a means for capacity building is anything to go by, informal groups should be considered a veritable means by managers in organization to stimulate member mentoring which has long-term implication on organizational performance.

\section{Suggested for Further Studies}

This study findings are limited to the telecommunication sector in Nigeria. We have recongised the operational and technological uniqueness of the sector especially in the face of the emerging market characteristics therefore, further research and perhaps with a large sample, be carried out in relation to the examined construct in other sectors like automobile spare parts manufacturing and distribution sector which has remarkable presence of groupings.

\section{References}

Adam, J. (2002). Towards a Theory of Organisational Politics. Organisational Development, 17(13)144 -162.

Aguero, C. I. (2007). Investigating Managerial Antecedents on Collaborative Practices and Predictions, Journal of Citizenship Behaviour, 7(4). 313-329.

Baraso, K. L. (1999). The Way of Corporate Entrepreneurship, Journal of Entrepreneurship Development, 10(11), 81-96.

Barayan, K.A and Mephil, F. (2007). Making them Great., Melbourne: Dave Pub Co.

Barego, N. W. (2000). The Goals of Emerging Forces and Cutting Down Responsibilities, Management Science Journal, $11(9), 72-88$

Baridam, D. (2008). Management and Organizational Theory, PortHarcourt: Sherbrooke Associates.

Barney, D. (2002). "Innovations in Performance Measurement: Trends and Research Implications", Journal of Management Accounting Research, 10, 205-238. 
Bazal, P.C. and Ledon, K.O. (2011). Role Specification: The Gender and Friendship Debate among Clinical Personnel. Social Psychology, 5(5), 423-436.

Chaharbagi, K. \& Cripps, S. (2006). Intellectual Capital: Direction, not Blind Faith, Journal of Intellectual Capital, 7(1), $29-42$.

Churchill, J.C., Matason, P., Abanaba, C.A and Rowland, O. S. (2007). Antecedents of Group Behaviour and Work Commitment, Social Psychology, 32(9), 196-207.

Creswell, J.W. (2003). Qualitative, Quantitative and Mixed Methods Approaches. Thousand Oaks CA: Sage Pub.

Danba, J. and Elliot, M.C. (2009). Formalizing Informal Relation for Effectiveness of Industrial Organizations, Journal of Change Management, 17(23), 118-131.

Daniel, M.O. (1996). Group Learning: Understanding the Functional Milieu, Organizational Psychology 4(11), 62-84.

Farveh, F. \& Osseh, E. (2012). The Effects of Informal Groups on Organizational Performance: A Case Study of IRAN Interdisciplinary, Journal of Contemporary Research in Business, 3(12), 364-374.

Gabbells, D.O. (2006). The Group Metaphor and Inclusiveness Tendencies of Minorities in Non Indigenous Mining Firms. Anthropological, 2(9), 312-318.

Gillas, O.J. (2007). Ethics and Groups: A Handbook on Workplace Ethics, Lagos: Gellaram Press.

Gray, B.J. Matear, S.M., Matheson, P.K. (2000). Improving the Performance of Hospitality Firms. International Journal of Hospitality Management, 12(3), 149-155.

Jackson, F.P and Miller, J. (2009). Managing Informal Networks: A Review, Contemporary Sociology, 5(11), $228-241$.

Jaja, S., \& Amingo, C. (2009). Organizational Cohesiveness and Employee Productivity, Journal of Business Studies, 2(4) 78-91.

Jaja, S.A. \& Chukwuigwe, E.C. (1998). Informal Groups at Work, Journal of Management Studies. 1(1), 23-34.

Jeremi, P.F. (2011). Casualization in Informal Group: The Dominance Methpher, Journal of Citizenship Behaviour, $11(26), 422-35$.

Johnnie, P.B. (1996). Organization Behaviour, Lagos: University Press Lagos.

Kaplan, R.S. \& Norton, D.P. (1992). Using the Balanced Score to Work. Journal of Business Review, 9(10), 134-147.

Kavcic, S \& Ivankovic, G. (2006). The Impact of Management Accounting System on Performance: An Explanatory Study of Hotels in Slovenia. Promises and Perils in Hospitality and Tourism Management, New Delhi: Aman

Lerry, P.C. (2007). In the Group: The Dynamics of Survival, Botswana: Phil and Nkabe Pub. Co.

Levin, C., \& Cross, A. (2004). Managing power: The Practical Work of Negotiating Interests. Proceedings of the 42nd Annual Adult Education Research Conference, 263-267. East Lansing, MI: Michigan State University.

Lincoln, Y.S. \& Guba, E.G. (1985). Naturalistic Inquiry, Newbury Park, CA: Sage Pub.

Miller, G. (1983) 'Sources, Procedures and Micro-economic Effects of Innovation', Journal of Economic Literature, 36, 1126-71.

Moro, L. (2009). Informal Groups: A Re-Interpretation of the Myths. Lagos: Balge Pub Co.

Morrison, R. (2003). Informal Relations in the Work Place: Associations with Job Satisfaction, Organizational Commitment and Turnover Intentions. New Zealand Journal of Psychology, 3, 114-128.

Nakisbe, O. (2004). Politics among Work Group: A Reason for Learning and Planning. Journal of Psychology, 4(6), 60-67.

Parasuanaman, P.C. (2007). Study on Relationship between Impression Management and Sustained Product Image in Pakistan, Journal of Business Review, 2(5), 102-113.

Pedrini, M. (2007). Human Capital Convergences in Intellectual Capital and Sustainability reports. Journal of Intellectual Capital, 8(2), 346-366.

Peter, N., \& Lucy, O. J. (2008). Making the Organization Efficient: The Different Levels of Involvement, Management Review, 11(8), 79-91.

Rogers, C. (2007). Informal Coalitions: Mastering the Hidden Dynamics of Organizational Change, New York: Palgrave Macmillan.

Rosenfeld, P., Giacalone, R. A., \& Riordan, C. A. (2002). Impression Management: Building and Enhancing 
Reputations at Work, London: Thomson Learning.

Sparrowe, L. W., Allen, R. W., \& Angle, H. L. (2001). The politics of upward influence in organizations. In L. L. Cummings \& B. M. Staw (Eds.), Research in Organizational Behavior, 3, 109-164. Greenwich, CT: JAI Press.

Tashakkori, A. (2009). Are we there yet? The State of Mixed Methods Community. Journal of Mixed Methods Research, 3, 287-291.

Van Vianen, A. E. M., \& DeDrew, C. K. W. (2001). Personality in Teams: Its Relationship to Social Cohesion, Task Cohesion, and Team Performance. European Journal of Work and Organizational Psychology, 10, 97-120.

\section{(c) EY EY}

This work is licensed under a Creative Commons Attribution 3.0 License. 